\title{
Development and Validation of Ultrasound Assisted and Dispersive Liquid-Liquid Microextractions Combined with HPLC-UV Method for Determination of Bosentan in Human Plasma and Urine
}

\author{
Sanaz Sajedi-Amin, ${ }^{a}$ Karim Asadpour-Zeynali, ${ }^{a}$ Maryam Khoubnasabjafari, ${ }^{b}$ \\ Farid Rashidi ${ }^{b}$ and Abolghasem Jouyban*,c, \\ ${ }^{a}$ Department of Analytical Chemistry, Faculty of Chemistry, University of Tabriz, 51664 Tabriz, Iran \\ ${ }^{b}$ Tuberculosis and Lung Disease Research Center, ${ }^{c}$ Kimia Idea Pardaz Azarbayjan (KIPA) Science \\ Based Company and 'Pharmaceutical Analysis Research Center and Faculty of Pharmacy, Tabriz \\ University of Medical Sciences, 51664 Tabriz, Iran
}

\begin{abstract}
A feasible, rapid, sensitive and reliable dispersive liquid-liquid microextraction (DLLME) and ultrasonic assisted liquid-liquid microextraction (USAEME) combined with high-performance liquid chromatography (HPLC) method with UV detection was developed and validated for analysis of bosentan in human plasma and urine samples. All validation tests were reported according to FDA guidelines. Since chromatographic methods are precise, accurate and provide excellent separation are increasingly being used in determination of trace amount of drugs in biological goals. So the optimized experimental extraction factors from our previous work were used to evaluate HPLC-UV method for decreasing the limit of quantifications (LOQs) to cover the therapeutic range. Simple centrifugation of urine samples was sufficient prior to microextraction procedure, while acetonitrile protein precipitation provides sample clean up for plasma samples. The suggested method was linear (correlation coefficient $R^{2}>0.998$ ) over a range of $0.1-10 \mu \mathrm{gL}^{-1}$ which covers the therapeutic range. Proposed methods are practical for quantitative analysis of bosentan in real samples, and could be used in routine clinical analyses.
\end{abstract}

Keywords: bosentan, liquid-liquid microextraction, DLLME, USAEME, RP-HPLC

\section{Introduction}

Bosentan monohydrate with molecular formula of $\mathrm{C}_{27} \mathrm{H}_{29} \mathrm{~N}_{5} \mathrm{O}_{6} \mathrm{~S} . \mathrm{H}_{2} \mathrm{O}$ belongs to a class of drugs known as endothelin receptor antagonists, which is used in pharmacotherapy of pulmonary hypertension. Bosentan tablets have been approved by FDA for the treatment of pulmonary arterial hypertension. Maximum serum concentration of bosentan ranged $959-1709 \mu \mathrm{g} \mathrm{L} \mathrm{L}^{-1}$ and the average time to reach the maximum concentration varied from 1 to 4 hours after an oral dose. Bosentan is mainly eliminated from the body by hepatic metabolism and subsequent biliary excretion of the metabolites and urinary excretion of the drug is $<3 \%$. The half-life of bosentan is 5 hours and its protein binding is $98 \%$. Bosentan's bioavailability is about $50 \%$ and is unaffected by food intake. The volume of distribution is about $18 \mathrm{~L}$ and total

*e-mail: ajouyban@hotmail.com clearance after a single intravenous dose is about $4 \mathrm{~L} \mathrm{~h}^{-1}$ in patients with pulmonary arterial hypertension. ${ }^{1-5}$

Quantification of drugs in biological matrices such as blood, serum and urine, is required in modern therapeutics to optimize a drug dosage according to personalized medicine strategies. In addition to clinical applications of these analyses, they are used in pharmaceutical industry to evaluate pharmacokinetic profile of a new drug and/or evaluating bioequivalency of a new oral drug formulation. To achieve these goals, a bioanalyst should employ a sensitive, selective, accurate, precise, repeatable and reliable analytical method. For routine analysis, simplicity, cost-effectiveness and the required skill levels for the method users should also be taken into account.

Liquid chromatography-mass spectrometry, ${ }^{6,7}$ ultra performance liquid chromatography, ${ }^{8}$ narrow bore high performance liquid chromatography, ${ }^{9}$ ultrafast liquid chromatography ${ }^{10}$ methods are available for determination of bosentan in plasma samples. Although reported methods are sensitive, they employ more expensive setups and are 
not available to be used in biomedical laboratories. To the best of our knowledge, there is no published method for determination of bosentan in human urine, so this work is aimed to develop and validate a simple and rapid method for determination of bosentan in human plasma and urine samples. Concerning the patient compliance, urine is more preferred biological sample when compared with serum and plasma. It is easier to be obtained and less invasive to the patients.

High-performance liquid chromatography (HPLC) methods, compared with other analytical methods, is gaining more interest for therapeutic drug monitoring (TDM). Due to the complexity of the biological matrices and low concentration of drugs in these samples, pretreatment step is necessary prior to chromatographic analysis. Hence, for TDM studies, a simple and fast procedure is preferred. Liquid-liquid extraction, ${ }^{11}$ solid-phase extraction, ${ }^{12}$ and protein precipitation (PPT) ${ }^{13}$ are the main techniques used to pretreat the samples prior to monitor levels of drugs in plasma, serum, and urine samples. These methods suffer from high consumption of organic solvents and relatively long processing time. To cover these drawbacks, several sample preparation techniques have been developed including solid-phase microextraction, ${ }^{14}$ hollow fiber-liquid phase microextraction, ${ }^{15}$ solidification of floating drop microextraction, ${ }^{16}$ single drop microextraction, ${ }^{17}$ vortex-assisted and ultrasound-assisted emulsification liquid-liquid microextraction (USAEME), ${ }^{18}$ dispersive liquid-liquid microextraction (DLLME), ${ }^{19-21}$ air-assisted liquid-liquid microextraction, ${ }^{22}$ ionic liquids in dispersive liquid-liquid microextraction ${ }^{23,24}$ and solid-phase extraction (SPE). ${ }^{25}$ DLLME and USAEME as microextraction-based techniques could be considered suitable alternative to the conventional extraction methods. DLLME and USAEME not only reduce consumption of organic solvent, but also reduce equilibration time because of the increased contact area between two immiscible phases. Recently, some DLLME-based methods combined with spectrofluorimetry, ${ }^{26}$ high performance liquid chromatographic-ultraviolet (HPLC-UV), ${ }^{27}$ capillary electrophoretic-ultraviolet (CE-UV) ${ }^{28,29}$ have been reported for determination of drugs in human plasma and urine samples. In a previous work, the applicability of the DLLME method as an efficient microextraction technique for bioanalysis was proposed and its results were compared with those of USAEME. ${ }^{30}$ The proposed spectrophotometric method was not sensitive enough for covering therapeutic range of bosentan. The present work is aimed to combine those microextraction methods with reversed phase high performance liquid chromatographic (RP-HPLC) measurement to develop and validate for determination of bosentan levels in plasma and urine samples. All validation tests for determination of bosentan in biological samples under the optimum conditions were reported according to FDA guidelines. ${ }^{2}$

\section{Experimental}

\section{Reagents}

Bosentan monohydrate was a gift from Danesh Pharmaceutical Company (Tehran, Iran). Molecular structures, $\log \mathrm{P}, \mathrm{pKa}$ values and therapeutic levels of bosentan are reported in Table 1. All the chemicals were of analytical grade, and the solvents were of HPLC grade. Acetonitrile, ethanol, methanol, acetone, tetrachloroethylene and chloroform were obtained from Scharlau (Barcelona, Spain). Sodium hydroxide, carbon tetrachloride, dichloromethane and ammonium acetate were purchased from Merck (Darmstadt, Germany). Deionized water was purchased from Shahid Ghazi Pharmaceutical Company (Tabriz, Iran). Drug-free quality control (QC) plasma samples were provided by Iranian Blood Transfusion Research Center (Tabriz, Iran) and

Table 1. Physicochemical properties of bosentan

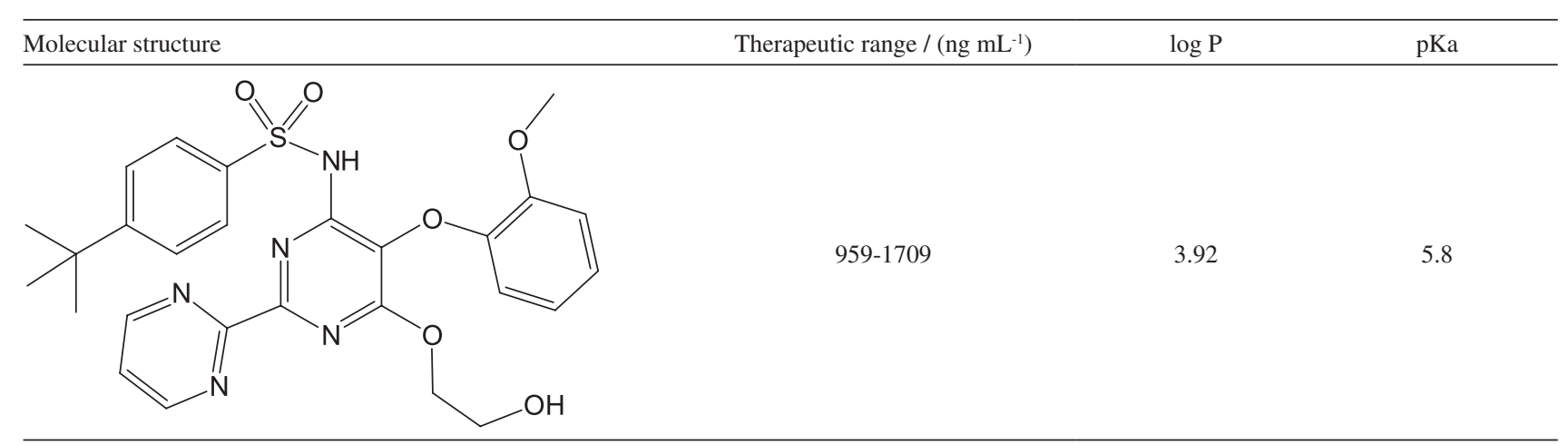

Physicochemical properties calculated using ACD/Labs software version 12.0. 
frozen in polypropylene microtubes at $-20^{\circ} \mathrm{C}$. Drug free urine samples were collected from healthy volunteers (who have not used any drug within last 3 months). In addition, real samples were collected from patients. Volunteers and patients signed a consent form which is approved by Ethics Committee of Tabriz University of Medical Sciences.

\section{Instrumentation}

The liquid chromatographic system consisted of a 1100 series pump, a 2-channel ERC-3315 degasser, a $1200 \mathrm{CE}$ detector UV-Vis and an interface box, all from Cecil (Cambridge, UK), the reversed-phase column was NovaPak $\mathrm{C}_{18}$ with dimensions of $4 \mu \mathrm{m}, 4.6 \mathrm{~mm} \times 150 \mathrm{~mm}$ from Waters Co. (Massachusetts, US). A vortex from Labtron Company (Tehran, Iran) was used in sample preparation. Sigma centrifuge (Osterode, Germany) was used in protein precipitation step and Hettich centrifuge (Tuttlingen, Germany) was used for sedimentation of the extraction solvent in sample preparation. $\mathrm{pH}$ adjustments were made by a Metrohm ${ }^{\circledast} \mathrm{pH}$ meter (Herisau, Switzerland). Alex ultrasonic (Istanbul, Turkey) was used for sonication of the samples.

\section{Standards and quality control samples preparation}

A $100 \mu \mathrm{g} \mathrm{mL} \mathrm{m}^{-1}$ stock solution of bosentan was prepared in methanol. Working solutions were daily prepared by serial dilutions of the stock solution. Plasma/urine sample standards that included the various levels of bosentan were prepared daily by dilution of appropriate amounts of the standard solution with the blank plasma/urine. Also, all plasma spiked samples were pretreated by PPT using 1:1 ratio of acetonitrile. All urine samples were centrifuged to eliminate any solid particles.

\section{Microextraction (DLLME and USAEME) procedures}

The urine/plasma QC spiked samples or patient samples were centrifuged/pretreated by PPT. Due to the high protein content of plasma and the "clogging" risk for the analytical column, all plasma samples were pretreated by PPT, and the supernatant was used for DLLME/USAEME for further enrichment and clean up. PPT was performed by a ratio of 1:1 (precipitant to plasma). For this purpose, methanol, ethanol, acetonitrile, or acetone are commonly used as a protein precipitant. With acetonitrile (as a precipitant), it was achieved a sufficient protein removal for quantitative analysis of the bosentan. Overall, mixture of precipitant and plasma were vortexed ( $30 \mathrm{~s}$ ) and centrifuged at $12000 \mathrm{rpm}$ for $5 \mathrm{~min}$.
Microextraction of bosentan from human urine/plasma was achieved using $1 \mathrm{~mL}$ of each sample. One $\mathrm{mL}$ of plasma colorless supernatant after PPT/urine was placed in a glass tube with conic bottom and diluted with deionized water up to $10 \mathrm{~mL}$. A mixture of $1250 \mu \mathrm{L}$ of acetonitrile (as dispersive solvent) and $200 \mu \mathrm{L}$ chloroform (as extraction solvent) was injected into a sample solution by using $2.0 \mathrm{~mL}$ syringe rapidly, so that a cloudy mixture was formed. The cloudy solution was centrifuged for $4 \mathrm{~min}$ at $4000 \mathrm{rpm}$. Accordingly, fine droplets of extraction phase were sedimented. The sedimented phase at the bottom of conical test tube was entirely transferred into a microtube, then evaporated to dryness under a stream of nitrogen. The residue was dissolved in $50 \mu \mathrm{L}$ of the mobile phase and injected to HPLC system.

To compare the extraction of sample in an organic solvent we also studied and optimized USAEME method. $1 \mathrm{~mL}$ sample was transferred into a microtube, $200 \mu \mathrm{L}$ chloroform was added as an organic extractant, sonicated for $5 \mathrm{~min}$, and finally the tubes were centrifuged for $4 \mathrm{~min}$ at $5000 \mathrm{rpm}$. The sedimented phase at the bottom of the tube was collected, then dried and dissolved in mobile phase and injected to HPLC system.

It should be noted that due to the remained acetonitrile content in the plasma samples after PPT, the USAEME method used in this work should be considered as a combination of both microextraction methods.

\section{Chromatographic conditions}

Isocratic elution using a mobile phase consisted of a mixture of acetonitrile and ammonium acetate buffer, adjusted at $\mathrm{pH} 3.5(70: 30 \mathrm{v} / \mathrm{v})$. The mobile phase was filtered through $0.45 \mu \mathrm{m}$ Millipore membrane filter and degassed by sonication before use. The peaks were detected at $270 \mathrm{~nm}$. The run time was $10 \mathrm{~min}$ and the flow rate was $1.0 \mathrm{~mL} \mathrm{~min}^{-1}$.

\section{Validation}

The HPLC-UV method for determination of bosentan in human urine/plasma was validated according to the FDA guidelines ${ }^{2}$ which include accuracy, precision, selectivity, linearity and robustness tests.

Calibration curves were constructed in the range of $0.2-10 \mu \mathrm{g} \mathrm{mL}^{-1}$ and $0.1-10 \mu \mathrm{g} \mathrm{mL}-1$ for spiked drug samples for plasma and urine, respectively. Standard solutions, and plasma/urine samples were injected in triplicates. The equations for the calibration curves and the correlation coefficients were calculated. The lowest and highest concentrations of the standard curves were defined as 
the lower limit of quantification (LLOQ) and upper limit of quantification (ULOQ) according to FDA validation guidelines.

The accuracy was checked by performing recovery studies. Recovery was calculated as the percentage relative error $(\mathrm{RE})=[($ assayed amount - real amount $) /$ real amount $] \times 100$. Low, middle and high concentration levels of drug spiked in QC samples, under optimum conditions were extracted and then analyzed. Each QC samples were performed in triplicates on three different days.

Drug stability in a biological fluid is a function of the storage conditions, the chemical properties of the drug, the matrix, and the container system. Stability studies were evaluated in freeze-thaw, short term and long term stability of the QC samples.

The selectivity of the proposed methods was proved by good resolution of the desired peak and other peaks of co-administered drugs. The interferences of various drugs in their maximum therapeutic amount with $2 \mu \mathrm{g} \mathrm{mL}^{-1}$ of bosentan, after extraction under the optimum condition showed no co-elution of any interfering peak with the target analyte peak.

The robustness of an analytical method is a measure of its capacity to remain unaffected by small, but deliberate variations in method parameters. It provides an indication of the procedure's reliability during normal usage because slight variations are expected when a method is transferred from one laboratory to another.

\section{Results and Discussion}

In our previous work, ${ }^{30}$ the effect of different parameters on DLLME and USAEME such as the type and volume of extracting solvent, type of dispersive solvent, salt addition, sample $\mathrm{pH}$, sonication time and centrifugation time and rate were investigated using one-factor-at-a-time method. Briefly, in DLLME the first and important experimental parameter is the selection of an extraction solvent to obtain an efficient extraction. According to the obtained results, chloroform was selected as extraction solvent due to its higher absorbance signal than other solvents. The effect of extraction solvent volume on the analytical signals was also investigated and $200 \mu \mathrm{L}$ was selected. In DLLME, a suitable disperser solvent has to be miscible with both aqueous and organic phases and form a cloudy state that increases contact area between the two phases. Dispersive solvents such as methanol, acetonitrile, ethanol and acetone, were examined and acetonitrile was selected as the dispersive solvent. The volume of dispersive solvent was also examined and $1250 \mu \mathrm{L}$ was selected as an optimum volume. For USAEME procedure, sonication time was optimized. Finally, the effect of $\mathrm{pH}$, centrifugation time and rate on the analytical signals were also investigated in both DLLME and USAEME procedure (for more details, see Table 2).

Table 2. Optimization of USAEME and DLLME reports

\begin{tabular}{lcc}
\hline Parameter & DLLME & USAEME \\
\hline Dispersive solvent / $\mu \mathrm{L}$ acetonitrile & 1250 & $\begin{array}{c}\text { remained } \\
\text { acetonitrile } \\
\text { from PPT }\end{array}$ \\
Extraction solvent / $\mu \mathrm{L}$ chloroform & 200 & 200 \\
$\mathrm{pH}$ & 5 & 5 \\
Centrifugation time / min & 4 & 6 \\
Centrifugation rate / rpm & 4000 & 5500 \\
Sample volume / $\mathrm{mL}$ & 7.5 & 1.0 \\
Sonication time / min & - & 4 \\
\hline
\end{tabular}

DLLME: dispersive liquid-liquid microextraction; USAEME: ultrasonic assisted liquid-liquid microextraction; PPT: protein precipitation.

The enrichment factor (EF) and overall extraction recovery $(\mathrm{ER} \%)$ were used to evaluate the efficiency of the proposed methods for extraction of bosentan from urine and plasma samples. The EF was defined as the ratio of the concentration of an analyte in the sedimented phase $\left(\mathrm{C}_{\mathrm{sed}}\right)$ to the initial concentration of the analyte $\left(\mathrm{C}_{0}\right)$ in the sample solution:

$\mathrm{EF}=\frac{\mathrm{C}_{\text {sed }}}{\mathrm{C}_{0}}$

where $\mathrm{C}_{\text {sed }}$ is calculated from a calibration curve obtained from direct injection of the standard solutions of drug.

The ER\% was defined as the percentage of total analyte amount $\left(\mathrm{n}_{0}\right)$, which is extracted to the organic phase $\left(\mathrm{n}_{\text {sed }}\right)$, and is a function of $\mathrm{EF}$ and the phase volume ratio $\left(\mathrm{V}_{\mathrm{sed}} / \mathrm{V}_{\mathrm{aq}}\right)$.

$\% \mathrm{ER}=\frac{\mathrm{n}_{\text {sed }}}{\mathrm{n}_{0}} \times 100=\frac{\mathrm{C}_{\text {sed }} \times \mathrm{V}_{\text {sed }}}{\mathrm{C}_{0} \times \mathrm{V}_{\text {aq }}} \times 100=\mathrm{EF} \times \frac{\mathrm{V}_{\text {sed }}}{\mathrm{V}_{\text {aq }}} \times 100$

where $\mathrm{V}_{\text {sed }}$ and $\mathrm{V}_{\mathrm{aq}}$ are the volumes of sediment phase and sample solution, respectively. The enrichment factors and extraction recoveries for DLLME and USAEME were 15.7-15.3 and 78.5-76.6\%, respectively.

\section{Method development and chromatographic conditions}

HPLC-UV method combined with microextraction procedure (DLLME or USAEME) was developed and validated for analyzing bosentan in urine and plasma samples. In this work, determination and separation of bosentan was done on $\mathrm{C}_{18}$ column and an isocratic mobile phase mode. To 
achieve separation of bosentan with minimal interferences in the shortest possible time from other components in human urine and plasma, the chromatographic conditions such as selection of a suitable absorbance wavelength, mobile phase composition, $\mathrm{pH}$ and flow rate were optimized. Excellent peak shape with good separation from matrix component was obtained from an isocratic mode with a mobile phase consisting of acetonitrile and ammonium acetate buffer pH $3.5(70: 30 \mathrm{v} / \mathrm{v})$. The flow rate was $1.0 \mathrm{~mL} \mathrm{~min}^{-1}$ and detection wavelength was set at $270 \mathrm{~nm}$. The bosentan retention time was determined $(\mathrm{RT}=2.54 \mathrm{~min})$ as shown in Figure 1. In isocratic elution, the run time of HPLC method should be as long as possible to elute all analytes from complex biological matrix in method development stage. It is obvious that one might set it for shorter run times after ensuring elution of the analyte of interest to speed up the analytical procedures.

Our method was successfully developed and proving to be accurate, reliable analytical method for use in laboratory to measure the concentration of bosentan. But in another case, the appropriate validation of analytical methods has become an essential part of successful drug development methods. To ensure that test results are reliable, regardless of the complexity of the sample matrix which can affect unseen issues on accuracy of test data, an adequate level of method validation is required. According to FDA guidelines, the required validation elements are accuracy, precision, selectivity, linearity and robustness tests.

\section{Selectivity}

The proposed method revealed no significant chromatographic peak within retention time around
2.54 minutes in blank urine and plasma samples from different individuals. Also there was no co-elution with any interfering peak(s) revealing the interference free analysis of bosentan.

\section{Linearity}

Under optimum conditions, calibration curves were plotted using the peak areas against concentrations of bosentan. Three consecutive calibration curves were used to assess precision and accuracy. Each curve was constructed employing nine concentration levels for plasma and urine samples. The linearity was analyzed through the average of three calibration curves for urine and plasma samples. Good linearities and the correlation coefficients $\mathrm{R}^{2}>0.99$ were obtained. The LLOQ/ULOQ was established as the lowest/ highest concentration on the calibration curve. Limits of detection (LOD) were evaluated on the basis of the signalto-noise ratio $(\mathrm{S} / \mathrm{N})$ of three. $\mathrm{S} / \mathrm{N}$ was estimated using measurements of the peak height relative to the baseline noise, and height values were consequently converted into concentrations through the height of the analyte peak set the LLOQ. All data which were calculated from the calibration curve collected can be seen in Table 3. The precision and accuracy at the low, medium and high concentrations $(0.2$, $1.0,3.0 \mu \mathrm{g} \mathrm{mL}^{-1}$ ) of bosentan in urine and plasma were assayed as shown in Table 4.

Intra- and inter-day precision (relative standard deviations, RSD\%) was within 5.7 and 3.9\%, respectively. Each QC samples were performed in triplicates on three different days. The percentage relative errors (RE\%) were ranged from $2.3-14.2 \%$ with percentage recoveries within $114 \%$, which indicated the accuracy of the proposed

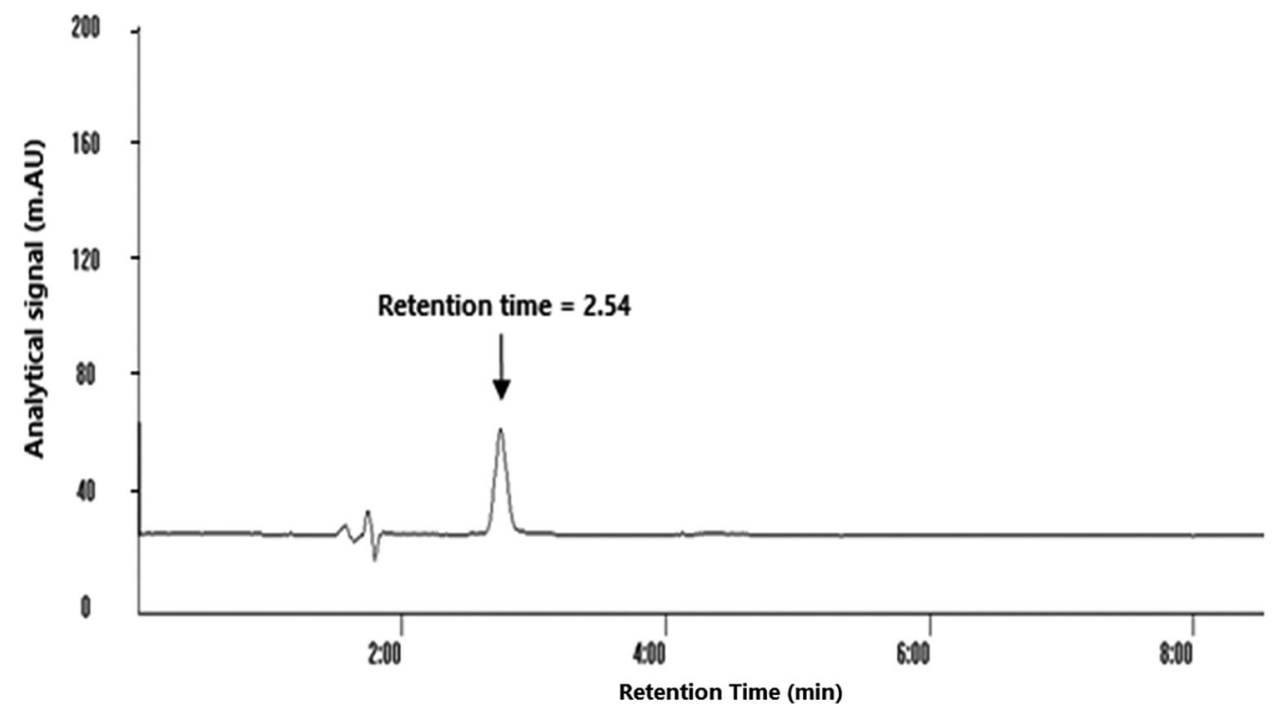

Figure 1. HPLC-UV chromatogram under optimum chromatographic condition of $5 \mu \mathrm{g} \mathrm{mL} \mathrm{m}^{-1}$ standard solution of bosentan. 
Table 3. The quantitative results of proposed methods for bosentan in human plasma/urine

\begin{tabular}{|c|c|c|c|c|}
\hline \multirow{2}{*}{ Parameter } & \multicolumn{2}{|c|}{ DLLME } & \multicolumn{2}{|c|}{ USAEME } \\
\hline & Urine & Plasma & Urine & Plasma \\
\hline Linear range / $\left(\mu \mathrm{g} \mathrm{mL}^{-1}\right)$ & $0.1-10$ & $0.2-10$ & $0.1-10$ & $0.2-10$ \\
\hline Slope (standard error of mean) & 540.82 & 247.27 & 608.09 & 586.67 \\
\hline Intercept (standard error of mean) & 23513 & 7443.4 & 25941 & 42685 \\
\hline $\mathrm{R}^{2}$ & 0.998 & 0.999 & 0.998 & 0.998 \\
\hline Number of data points & 9 & 9 & 9 & 9 \\
\hline $\mathrm{LOD} /\left(\mu \mathrm{g} \mathrm{mL}^{-1}\right)$ & 0.085 & 0.073 & 0.078 & 0.078 \\
\hline $\mathrm{LLOQ} /\left(\mu \mathrm{g} \mathrm{mL} L^{-1}\right)$ & 0.1 & 0.2 & 0.1 & 0.2 \\
\hline $\mathrm{ULOQ} /\left(\mu \mathrm{g} \mathrm{mL}{ }^{-1}\right)$ & 10 & 10 & 10 & 10 \\
\hline
\end{tabular}

DLLME: dispersive liquid-liquid microextraction; USAEME: ultrasonic assisted liquid-liquid microextraction; LOD: limit of detection; LLOQ: lower limit of quantification; ULOQ: upper limit of quantification.

Table 4. Assay precision and accuracy of QC samples if assuming the optimal extraction and analysis conditions

\begin{tabular}{|c|c|c|c|c|c|c|c|c|c|}
\hline \multirow[b]{2}{*}{ Sample } & \multirow{2}{*}{$\begin{array}{c}\text { Nominal } \\
\text { concentration / } \\
\left(\mu \mathrm{gLL}^{-1}\right)\end{array}$} & \multicolumn{4}{|c|}{ DLLME } & \multicolumn{4}{|c|}{ USAEME } \\
\hline & & $\begin{array}{l}\text { Intra-assay } \\
\text { precision } \\
(\mathrm{RSD} \%)\end{array}$ & $\begin{array}{c}\text { Accuracy } \\
\text { (RE\%) }\end{array}$ & $\begin{array}{l}\text { Inter-assay } \\
\text { precision } \\
(\mathrm{RSD} \%)\end{array}$ & $\begin{array}{c}\text { Accuracy } \\
\text { (RE\%) }\end{array}$ & $\begin{array}{l}\text { Inter-assay } \\
\text { precision } \\
(\mathrm{RSD} \%)\end{array}$ & $\begin{array}{c}\text { Accuracy } \\
\text { (RE\%) }\end{array}$ & $\begin{array}{l}\text { Intra-assay } \\
\text { precision } \\
(\mathrm{RSD} \%)\end{array}$ & $\begin{array}{c}\text { Accuracy } \\
\text { (RE\%) }\end{array}$ \\
\hline \multirow{3}{*}{ Plasma } & 0.2 & 2.9 & -9.8 & 1.4 & -5.0 & 4.4 & -14.2 & 1.8 & -8.0 \\
\hline & 1.0 & 5.7 & 9.0 & 3.9 & 6.0 & 3.8 & 4.3 & 2.3 & 3.0 \\
\hline & 3.0 & 2.2 & -2.3 & 1.3 & -4.0 & 2.4 & -4.0 & 2.8 & -7.0 \\
\hline \multirow{3}{*}{ Urine } & 0.2 & 4.0 & 8.0 & 3.6 & 8.2 & 5.8 & 8.4 & 1.1 & -5.0 \\
\hline & 1.0 & 3.8 & -8.0 & 2.8 & -9.0 & 3.2 & -5.0 & 3.7 & -7.0 \\
\hline & 3.0 & 3.6 & -3.7 & 3.3 & -4.0 & 1.3 & -4.0 & 1.6 & -4.0 \\
\hline
\end{tabular}

DLLME: dispersive liquid-liquid microextraction; USAEME: ultrasonic assisted liquid-liquid microextraction; RSD: relative standard deviation; RE: relative error.

method. All stability experiments showed percentage relative errors within $6.8 \%$ (see Table 5 for details).

The $\%$ RE of robustness testing under different altered conditions is given in Table 6, indicating that the current method is robust.

\section{Real samples}

To demonstrate the capability of the DLLME and USAEME combined with HPLC-UV system for the analysis of bosentan in real samples, plasma and urine samples

Table 5. Stability data of bosentan analysis in plasma and urine samples

\begin{tabular}{|c|c|c|c|c|c|c|c|}
\hline \multirow[b]{2}{*}{ Sample } & \multirow[b]{2}{*}{$\begin{array}{l}\text { Concentration / } \\
\quad\left(\mu \mathrm{g} \mathrm{mL}^{-1}\right)\end{array}$} & \multicolumn{2}{|c|}{ Room temperature stability } & \multicolumn{2}{|c|}{$-4{ }^{\circ} \mathrm{C}$} & \multicolumn{2}{|c|}{ Freeze-thaw stability } \\
\hline & & $\begin{array}{c}\text { Found } \\
\text { concentration- } \\
\text { DLLME (RE\%) / } \\
\left(\mu \mathrm{g} \mathrm{mL} L^{-1}\right)\end{array}$ & $\begin{array}{c}\text { Found } \\
\text { concentration- } \\
\text { USAEME }(\mathrm{RE} \%) / \\
\left(\mu \mathrm{g} \mathrm{mL} \mathrm{mL}^{-1}\right)\end{array}$ & $\begin{array}{c}\text { Found } \\
\text { concentration- } \\
\text { DLLME (RE\%) / } \\
\left(\mu \mathrm{g} \mathrm{mL} \mathrm{mL}^{-1}\right)\end{array}$ & $\begin{array}{c}\text { Found } \\
\text { concentration- } \\
\text { USAEME }(\mathrm{RE} \%) / \\
(\mu \mathrm{g} \mathrm{mL}-1)\end{array}$ & $\begin{array}{c}\text { Found } \\
\text { concentration- } \\
\text { DLLME }(\mathrm{RE} \%) / \\
\left(\mu \mathrm{g} \mathrm{mL}^{-1}\right)\end{array}$ & $\begin{array}{c}\text { Found } \\
\text { concentration- } \\
\text { USAEME }(\mathrm{RE} \%) / \\
\left(\mu \mathrm{g} \mathrm{mL} \mathrm{mL}^{-1}\right)\end{array}$ \\
\hline \multirow{3}{*}{ Plasma } & 0.2 & $0.20(3.3)$ & $0.21(5.0)$ & $0.20(3.3)$ & $0.21(2.8)$ & $0.20(2.7)$ & $0.21(2.0)$ \\
\hline & 1.0 & $1.01(1.3)$ & $0.97(2.3)$ & $1.09(8.9)$ & $1.05(4.7)$ & $1.08(7.5)$ & $1.03(3.1)$ \\
\hline & 3.0 & $3.11(3.7)$ & $3.23(7.7)$ & $3.12(3.0)$ & $3.25(8.5)$ & $3.11(1.2)$ & $3.14(4.4)$ \\
\hline \multirow{3}{*}{ Urine } & 0.2 & $0.20(1.5)$ & $0.21(5.0)$ & $0.20(1.7)$ & $0.21(5.1)$ & $0.21(5.1)$ & $0.21(5.2)$ \\
\hline & 1.0 & $1.01(1.3)$ & $1.02(2.3)$ & $1.09(8.9)$ & $1.02(2.3)$ & $1.08(7.5)$ & $1.02(1.5)$ \\
\hline & 3.0 & $3.11(3.7)$ & $3.06(2.0)$ & $3.09(3.0)$ & $3.08(2.5)$ & $3.04(1.2)$ & $3.06(2.2)$ \\
\hline
\end{tabular}

DLLME: dispersive liquid-liquid microextraction; USAEME: ultrasonic assisted liquid-liquid microextraction; RE: relative error. 
Table 6. The robustness results of proposed methods for bosentan in human plasma/urine

\begin{tabular}{|c|c|c|c|c|c|}
\hline \multirow{2}{*}{ Level } & \multirow{2}{*}{$\begin{array}{l}\text { Nominal concentration / } \\
\qquad\left(\mu \mathrm{g} \mathrm{mL}^{-1}\right)\end{array}$} & \multicolumn{2}{|c|}{ DLLME } & \multicolumn{2}{|c|}{ USAEME } \\
\hline & & Urine (recovery) / \% & Plasma (recovery) / \% & Urine (recovery) / \% & Plasma (recovery) $/ \%$ \\
\hline 1 & 1.0 & $0.97(97)$ & $1.05(105)$ & $0.98(98)$ & 1.09 (109) \\
\hline 2 & 1.0 & $0.93(93)$ & $1.06(106)$ & $0.96(95)$ & $1.05(105)$ \\
\hline 3 & 1.0 & $0.95(95)$ & $1.01(101)$ & $0.93(93)$ & $0.99(99)$ \\
\hline
\end{tabular}

DLLME: (1) $\mathrm{pH}=4.5$, dispersive solvent volume: $1200 \mu \mathrm{L}$, extraction solvent volume: $175 \mu \mathrm{L}$, speed of centrifugation: $3500 \mathrm{rpm}$; (2) $\mathrm{pH}=5$, dispersive solvent volume: $1250 \mu \mathrm{L}$, extraction solvent volume: $200 \mu \mathrm{L}$, speed of centrifugation: $4000 \mathrm{rpm}$; (3) $\mathrm{pH}=5$, dispersive solvent volume: $1300 \mu \mathrm{L}$, extraction solvent volume: $225 \mu \mathrm{L}$, speed of centrifugation: $4500 \mathrm{rpm}$. USAEME: (1) $\mathrm{pH}=4.5$, extraction solvent volume: $175 \mu \mathrm{L}$, sonication time: $3.5 \mathrm{~min}$, speed of centrifugation: $5200 \mathrm{rpm}$; (2) $\mathrm{pH}=5$, extraction solvent volume: $200 \mu \mathrm{L}$, sonication time: 4 min, speed of centrifugation: $5500 \mathrm{rpm}$; (3) pH = 5.5, extraction solvent volume: $220 \mu \mathrm{L}$, sonication time: $4.5 \mathrm{~min}$, speed of centrifugation: $5800 \mathrm{rpm}$.

were collected from patients under pharmacotherapy of pulmonary arterial hypertension whom all patients gave their written admission, and blood samples were collected after oral administration of bosentan. Venous blood $(5 \mathrm{~mL})$ was collected in EDTA, and plasma harvested. Samples were then frozen at $-4{ }^{\circ} \mathrm{C}$ until analysis time.

The plasma and urine bosentan levels of all studied patients were in the range of calibration curve, details of real samples are given in Figures 2 and 3 and Table 7.

As seen on Figures 2 and 3 , there is a difference between two methods at the beginning of their chromatograms. The difference is related to the presence of dispersive solvent. In DLLME procedure, dispersive solvent not only expands the interfacial area, but also provides extra clean up, so in comparison with USAEME, it is more profitable for analyzing drug in complex matrices such as biological samples. Our observations reveal that the chromatograms of the DLLME samples are clearer than those of USAEME. This is possibly due to the solubilization of acetonitrile added in the dispersion phase on proteins and other background materials in plasma sample for DLLME method. More solubility of these materials in aqueous phase will result in low extraction in the organic phase, which will result in more clean up.

\section{Comparison with other work}

A comparison of characteristic performance data of the proposed microextraction-analysis methods (DLLME and USAEME) with the literature methods for determination of bosentan in biological matrices is given in Table 8 . Only a few reports cover the determination of bosentan in biological samples. ${ }^{31-38}$ As we aimed to develop and validate a simple and rapid method for determination of bosentan in biological matrices, we compared with some of those which studied in biological fluids. In our recent

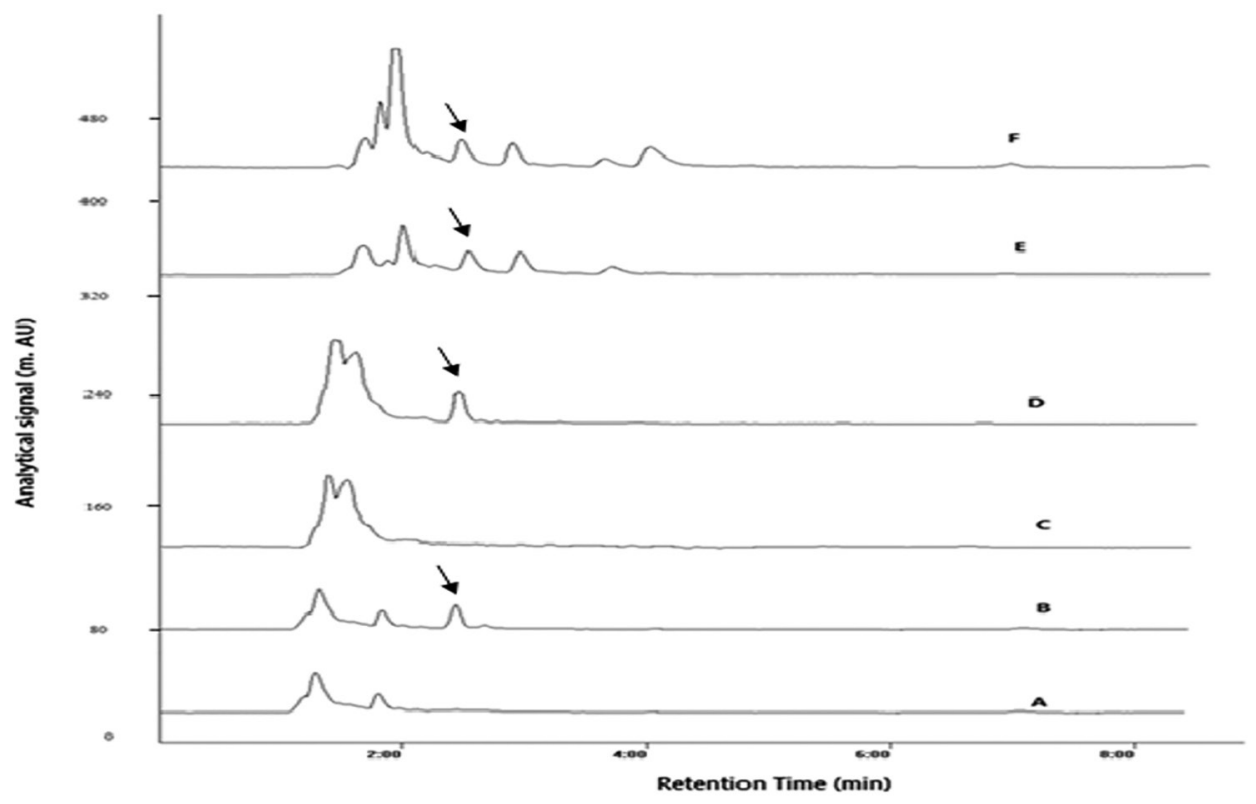

Figure 2. Typical urine chromatograms of (A) blank healthy volunteer (DLLME); (B) spiked $0.3 \mu \mathrm{g} \mathrm{mL}{ }^{-1}$ (DLLME); (C) blank healthy volunteer (USAEME); (D) spiked $0.3 \mu \mathrm{g} \mathrm{mL}^{-1}$ (USAEME); (E) patient sample (DLLME); (F) patient sample (USAEME). 


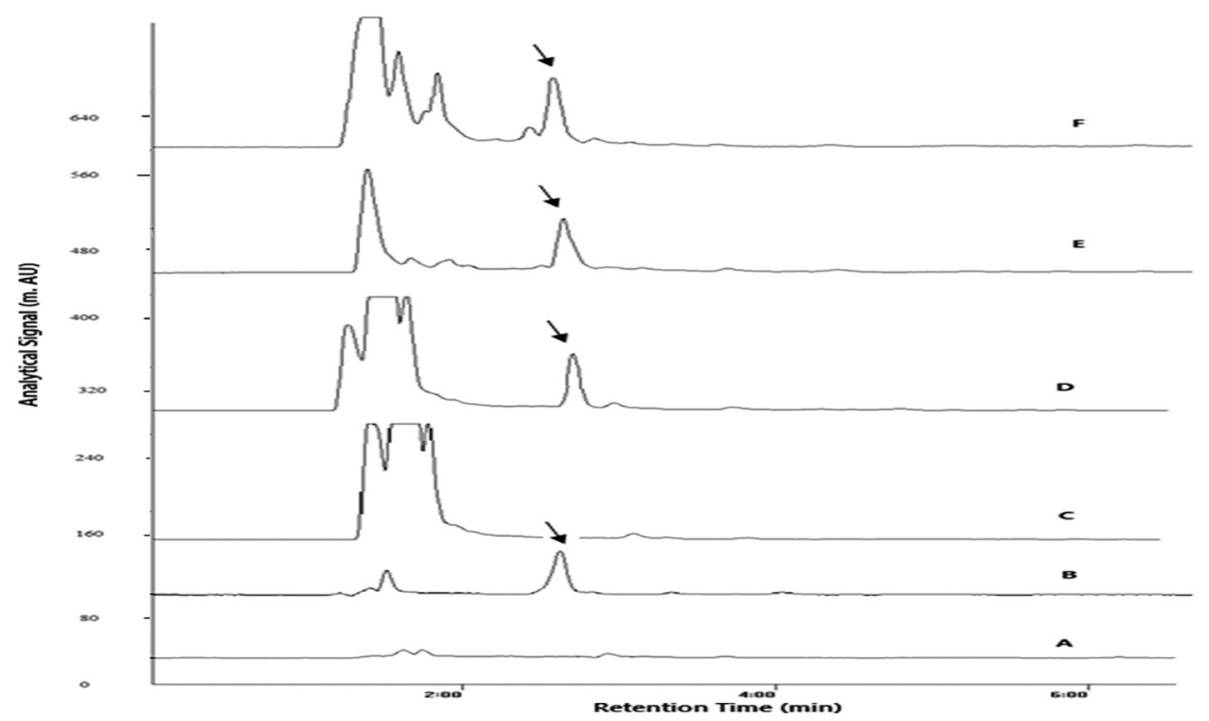

Figure 3. Typical plasma chromatograms of (A) blank healthy volunteer (DLLME); (B) spiked $0.5 \mu \mathrm{g} \mathrm{mL}^{-1}$ (DLLME); (C) blank healthy volunteer (USAEME); (D) spiked $0.5 \mu \mathrm{g} \mathrm{mL} \mathrm{m}^{-1}$ (USAEME); (E) patient sample (DLLME); (F) patient sample (USAEME).

Table 7. Some details of the real samples analyzed by the proposed methods and their bosentan concentration

\begin{tabular}{|c|c|c|c|c|c|c|c|c|c|c|}
\hline \multirow[t]{2}{*}{ No. } & \multirow[t]{2}{*}{ Gender } & \multirow[t]{2}{*}{ Age } & \multirow{2}{*}{$\begin{array}{l}\text { Bosentan daily } \\
\text { dosage / mg }\end{array}$} & \multirow{2}{*}{$\begin{array}{l}\text { Duration of } \\
\text { dairy intake }\end{array}$} & \multirow{2}{*}{$\begin{array}{c}\text { Co-administered } \\
\text { drugs }\end{array}$} & \multirow{2}{*}{$\begin{array}{l}\text { Intake } \\
\text { time / h }\end{array}$} & \multicolumn{2}{|c|}{$\begin{array}{c}\text { Concentration plasma / } \\
\left.(\mu \mathrm{g} \mathrm{mL})^{-1}\right)\end{array}$} & \multicolumn{2}{|c|}{$\begin{array}{c}\text { Concentration urine / } \\
\left.\qquad(\mu \mathrm{g} \mathrm{mL})^{-1}\right)\end{array}$} \\
\hline & & & & & & & DLLME & USAEME & DLLME & USAEME \\
\hline 1 & female & 25 & 125 b.i.d. & 45 days & $\begin{array}{c}\text { warfarin digoxin } \\
\text { furosemide sildenafil } \\
\text { lisinopril }\end{array}$ & 10 & 0.571 & 0.556 & 0.126 & 0.119 \\
\hline 2 & female & 50 & 125 b.i.d. & 2 years & $\begin{array}{c}\text { warfarin sildenafil } \\
\text { aspirin }\end{array}$ & 14 & 0.625 & 0.612 & 0.191 & 0.182 \\
\hline 3 & female & 19 & 62.5 b.i.d. & 9 month & $\begin{array}{c}\text { carvedilol aspirin } \\
\text { spironolactone losartan }\end{array}$ & 15 & 0.214 & 0.201 & - & - \\
\hline
\end{tabular}

b.i.d.: twice-daily dosing.

Table 8. Characteristic performance data obtained by using USAEME, DLLME and other techniques in the determination of bosentan in biological matrices

\begin{tabular}{|c|c|c|c|c|c|c|}
\hline Extraction method & Detection system & & LLOQ / (ng mL $\left.{ }^{-1}\right)$ & $\begin{array}{c}\text { Linear range / } \\
\left(\text { ng } \mathrm{mL}^{-1}\right)\end{array}$ & Sample & Reference \\
\hline SPE & narrow bore HPLC-MS-MS & & 1.0 & 1.0-10000 & biological matrices & 9 \\
\hline SPE & LC-MS/MS & & 2.0 & $2.0-1000$ & plasma & 6 \\
\hline- & UPLC-MS/MS & & 1.0 & $5.0-1000$ & human plasma & 8 \\
\hline- & UFLC-MS/MS & & 0.5 & $0.5-2000$ & rat plasma & 10 \\
\hline \multirow[t]{7}{*}{ SPE and LLE } & LC-MS/MS & A & 0.5 & $0.5-200$ & human plasma & 7 \\
\hline & & B & 0.5 & $0.5-200$ & human plasma & \\
\hline & & $\mathrm{C}$ & 2.0 & $2.0-1000$ & human plasma & \\
\hline & & $\mathrm{D}$ & 2.0 & $2.0-1000$ & human plasma & \\
\hline & & $\mathrm{E}$ & 5.0 & $5.0-1000$ & plasma, rat, dog & \\
\hline & & $\mathrm{F}$ & 1.0 & $1.0-1000$ & plasma, rat & \\
\hline & & $\mathrm{G}$ & 2.0 & $2.0-1000$ & plasma & \\
\hline \multirow[t]{2}{*}{ DLLME and USAEME } & UV-Vis & & 1000 & $1000-5000$ & human plasma and urine & 30 \\
\hline & & & 1000 & $1000-5000$ & & \\
\hline \multirow[t]{2}{*}{ DLLME } & HPLC-UV & & 100 & $100-10000$ & human urine & this work \\
\hline & & & 200 & $200-10000$ & human plasma & \\
\hline \multirow[t]{2}{*}{ USAEME } & HPLC-UV & & 100 & $100-10000$ & human urine & this work \\
\hline & & & 200 & $200-10000$ & human plasma & \\
\hline
\end{tabular}


work, ${ }^{30}$ liquid-liquid microextractions were employed. As seen in Table 8 , the previously proposed method $^{30}$ is not able to cover the therapeutic range and this complementary work is conducted to decrease the LOQs and provides a practical analytical method to determine bosentan without interference from other compounds present in the samples. In the literature, ${ }^{6,79}$ two kinds of sample preparation methods such as liquid-liquid extraction and solid phase extraction have been developed. Nevertheless, these conventional extraction methods are time-consuming and require large volumes of samples and toxic organic solvents. Microextraction techniques due to many advantages which overcome the drawbacks of classic extraction techniques are more attractive. DLLME and USAEME are easy, solvent and cost saving procedures. In spite of developments in modern analytical instruments ${ }^{6-9}$ with better LLOQs and linearity ranges, high cost of analysis make them not applicable for routine clinical applications. These microextraction methods also provided reasonable results for extraction of aluminum from urine samples after complexation with 8-hydroxy quinoline. ${ }^{39}$

\section{Conclusion}

In this work, a reversed-phase HPLC-UV method was developed and validated for determination of bosentan in human plasma and urine samples. This study provided a simple, low operation cost liquid-liquid microextraction methods (DLLME and USAEME) and satisfyingly applied to the analysis of bosentan in human urine and plasma. The proposed method provides a simple analytical procedure in bioanalysis, pharmaceutical and TDM investigations.

\section{Acknowledgments}

The authors thank the reviewers' comments on this submission and Danesh Pharmaceutical Company for gifting bosentan powder.

\section{References}

1. http://www.Drugbank.ca/drugs/DB00559, accessed in August 2016.

2. United States Food and Drug Administration (US-FDA), Center for Drug Evaluation and Research (CDER); https://www. accessdata.fda.gov/scripts/cder/drugsatfda/, accessed in August 2016.

3. Buck, M. L.; Pediatr. Pharmacother. 2011, 17, 11.

4. Dingemans, J.; VanGiersbergen, P. L.; Clin. Pharmacokinet. 2004, 43, 1089.
5. Azim, S.; Husain, A.; Mitra, M.; Bhasin, P. S.; Am. J. PharmTech. Res. 2012, 4, 135.

6. Yokoyama, Y.; Tomatsuri, M.; Hayashi, H.; Hirai, K.; Ono, Y.; Yamada, Y.; Todoroki, K.; J. Pharm. Biomed. Anal. 2014, 89, 227.

7. Dell, D.; Lauscker, B.; Hopfgartner, G.; Vangiersbergen, P. L. M.; Chromatographia 2002, 55, 115.

8. Xiangjun, Q.; Jianlong, Zh.; Zhe, W.; Zhisheng, X.; Ren-ai, X.; J. Pharm. Biomed. Anal. 2014, 95, 207.

9. Lausecker, B.; Hess, B.; Fischer, G.; Mueller, M.; Hopfgartner, G.; J. Chromatogr. B: Biomed. Sci. Appl. 2000, 749, 67.

10. Alptug, A.; Murat, O.; Kadioglu, Y.; Halici, Z.; Turkan, D.; Yayla, M.; Un, H.; J. Pharm. Biomed. Anal. 2014, 97, 33.

11. Deventer, K.; VanEenoo, P.; Delbeke, F. T.; Rapid Commun. Mass Spectrom. 2005, 19, 90.

12. Maurer, H. H.; Tenberken, O.; Kratzsch, C.; Weber, A. A.; Peters, F. T.; J. Chromatogr. A 2004, 1058, 169.

13. Soltani, S.; Jouyban, A.; Bioanalysis 2014, 4, 41.

14. Hu, X.; Pan, J.; Hu, Y.; Li, G.; J. Chromatogr. A 2009, 1216, 190.

15. Liu, W.; Zhang, L.; Wei, Z.; Chen, S.; Chen, G.; J. Chromatogr. A 2009, 1216, 3054.

16. Yamini, Y.; Ghambarian, M.; Khalili-Zanjani, M. R.; Faraji, M.; Shariati, S.; J. Sep. Sci. 2009, 32, 3201.

17. Batlle, R.; Nerín, C.; J. Chromatogr. A 2004, 1045, 29.

18. Zhang, Y.; Lee, H. K.; J. Chromatogr. A 2013, 1274, 28.

19. Farahani, H.; Norouzi, P.; Dinarvand, R.; Ganjali, M. R.; J. Chromatogr. A 2007, 1172, 105.

20. Liang, P.; Xu, J.; Li, Q.; Anal. Chim. Acta 2008, 609, 53.

21. Ranjbari, E.; Hadjmohammadi, M. R.; Talanta 2012, 100, 447.

22. Farajzadeh, M. A.; Afsharmoghaddam, M. R.; Anal. Chim. Acta 2012, 728, 31.

23. Zhang, H.; Chen, X.; Jiang, X.; Anal. Chim. Acta 2009, 689, 137.

24. Trujillo-Rodríguez, M. J.; Rocio-Bautista, P.; Pino, V.; Afonso, A. M.; Trends Anal. Chem. 2013, 51, 87.

25. Zhao, R. S.; Wang, X.; Yuan, J. P.; Lin, J. M.; J. Chromatogr. A 2008, 1183, 15.

26. Zamani-Kalajahi, M.; Fazeli-Bakhtiyari, R.; Amiri, M.; Golmohammadi, A.; Afrasiabi, A.; Khoubnasabjafari, M.; Jouyban, A.; Bioanalysis 2013, 5, 437.

27. Khoubnasabjafari, M.; Ansarin, Kh.; Jouyban-Gharamaleki, V.; Panahi-Azar, V.; Shayanfar, A.; Mohammadzadeh, L.; Jouyban, A.; J. Pharm. Pharm. Sci. 2015, 18, 207.

28. Hamidi, S.; Soltani, S.; Jouyban, A.; Bioanalysis 2015, 7, 1107.

29. Hamidi, S.; Jouyban, A.; Anal. Methods 2015, 7, 5820.

30. Sajedi-Amin, S.; Assadpour-Zeynali, K.; Panahi-Azar, V.; Kebriaeezadeh, A.; Khoubnasabjafari, M.; Ansarin, Kh.; Jouyban-Gharamaleki, V.; Jouyban, A., BioImpacts 2015, 5, 191. 
31. Souvik, D.; Narendra, A.; Raja Kumar, V.; Mathrusri Annapurna, M.; J. Pharm. Educ. Res. 2010, 1, 73.

32. Kalaichelvi, R.; Jayachandran, E.; Int. J. Pharm. Chem. Sci. 2013, 2, 837.

33. Annapurna, M. M.; Pavani, S.; Anusha, S.; Harika, M.; Indo Am. J. Pharm. Res. 2013, 3, 4528.

34. Atila, A.; Yilmaz, B.; Iran. J. Pharm. Res. 2015, 14, 443.

35. Lavudu, P.; Rani, A. P.; Sekaran, Ch. B.; Ramesh, A.; Kumar, A. A.; Chem. Sci. Trans. 2014, 3, 1242.

36. Khan, M. A.; Sinha, S.; Todkar, M.; Parashar, V.; Reddy, K. S.; Am. J. Sci. Ind. Res. 2012, 3, 69.
37. Sujatha, K.; Palavan, C.; Seshagiri, J. V. L. N.; Am. J. Pharm. Tech. Res. 2013, 3, 674.

38. Muralidharan, S.; Kumar, J. R.; Am. J. Anal. Chem. 2012, 3, 715.

39. Farajbakhsh, F.; Amjadi, M.; Manzoori, J.; Ardalan, M. R.; Jouyban, A.; Pharm. Sci. 2016, 22, 87.

Submitted: May 7, 2016 Published online: August 18, 2016 